University of Nebraska - Lincoln

DigitalCommons@University of Nebraska - Lincoln

Faculty Publications in Educational

Administration

Educational Administration, Department of

2017

\title{
Exploring Integrative Learning in Service-Based Alternative Breaks
}

\author{
Elizabeth Niehaus \\ University of Nebraska-Lincoln, eniehaus@unl.edu \\ Courtney Holder \\ University of Maryland-College Park, cholder@umd.edu \\ Mark Rivera \\ University of Maryland-College Park \\ Crystal E. Garcia \\ University of Nebraska-Lincoln, crystalgarcia@unl.edu \\ Taylor C. Woodman \\ University of Maryland-College Park, tcw@gwu.edu
}

See next page for additional authors

Follow this and additional works at: https://digitalcommons.unl.edu/cehsedadfacpub

Part of the Educational Administration and Supervision Commons

Niehaus, Elizabeth; Holder, Courtney; Rivera, Mark; Garcia, Crystal E.; Woodman, Taylor C.; and Dierberger, Julie, "Exploring Integrative Learning in Service-Based Alternative Breaks" (2017). Faculty Publications in Educational Administration. 49.

https://digitalcommons.unl.edu/cehsedadfacpub/49

This Article is brought to you for free and open access by the Educational Administration, Department of at DigitalCommons@University of Nebraska - Lincoln. It has been accepted for inclusion in Faculty Publications in Educational Administration by an authorized administrator of DigitalCommons@University of Nebraska - Lincoln. 


\section{Authors}

Elizabeth Niehaus, Courtney Holder, Mark Rivera, Crystal E. Garcia, Taylor C. Woodman, and Julie Dierberger 


\title{
Exploring Integrative Learning in Service-Based Alternative Breaks
}

\author{
Elizabeth Niehaus, ${ }_{1}$ Courtney Holder, ${ }^{2}$ Mark Rivera, $^{3}$ \\ Crystal E. Garcia, ${ }^{1}$ Taylor C. Woodman, ${ }^{4}$ and Julie Dierberger ${ }^{5}$
}

1 Department of Educational Administration, University of Nebraska-Lincoln, Lincoln, Nebraska

2 Leadership Studies, University of Maryland-College Park, College Park, Maryland

3 Main Administration Building, University of Maryland-College Park, College Park, Maryland 4 Higher Education, Student Affairs, and International Education Policy, University of Maryland-College Park, College Park, Maryland

5 Omaha Service Learning Academy, University of Nebraska, Lincoln, Nebraska,

Corresponding author — Elizabeth Niehaus eniehaus@unl.edu

\begin{abstract}
The purpose of this study was to explore how students integrate learning from one particular experience, participating in a service learning-based alternative break $(A B)$, with other postsecondary experiences and to identify the conditions that may facilitate integrative learning. Using qualitative case studies combined with narrative analysis, we analyzed data from interviews with 38 AB participants. Consistent with Barber's (2012) theory of integrative learning, we found evidence that students were engaging in the processes of connecting, applying, and synthesizing learning from their ABs. We identified the importance of interacting with diverse others in facilitating integrative learning, but also noted barriers to integration such as difficulty connecting information across disparate contexts. Through exploring integrative learning in one particular context, the findings from this study can inform our understanding of how students are engaging in integration and improve our understanding of how educators can best support integration in higher education.
\end{abstract}

Keywords: Alternative breaks; integrative learning; service, learning

In her 2012 Presidential Address to the Association for the Study of Higher Education, Neumann (2014) called on higher education scholars to "stake a claim" on learning. Neumann noted that learning is deeply rooted in prior knowledge and that "learning in higher education emerges when a student acknowledges and works through differences between her or his prior views and beliefs and new ideas that instructors or texts represent" (p. 251). This idea that the process of learning is fundamentally a process of connecting and applying ideas across contexts and of synthesizing new and old ideas positions learning as a process of integration. Scholars, policymakers, and organizations have recognized that 
the ability to integrate knowledge across contexts is a key skill for 21st-century learners (e.g., Hovland, Anderson, \& Ferren, 2015; Mansilla, 2008). Students' ability to integrate learning has also been empirically connected to students' overall cognitive development, problem- solving skills, self-awareness, and civic responsibility (e.g., Nelson Laird, Seifert, Pascarella, Mayhew, \& Blaich, 2014; Wang, Pascarella, Nelson Laird, \& Ribera, 2015), all of which are "key competencies in today's knowledge society" (Mansilla, 2008, p. 31).

Despite the importance of facilitating students' ability to engage in integrative learning and evidence that integration is associated with other desirable outcomes, little research has explored how students engage in integration and how particular educational contexts facilitate students' ability to do so (Barber, 2012 , 2014). This lack of research is particularly concerning, as there is evidence that educators are failing to fully capitalize on students in-classroom and outof-classroom experiences to promote integrative learning (Barber, 2012). Barber (2014) and Wawrzynski and Baldwin (2014) argued that high-impact practices such as service-learning may be particularly well suited to promote the integration of learning. The very nature of service-learning is about connecting community service with academic learning, either in or out of the classroom. Eyler and Giles (1999) argued that "any program that attempts to link academic study with service can be characterized as service-learning" (p. 5); they also emphasized, however, that "not all service-learning efforts may help students attain all the goals that practitioners hope for" (p. 5) and pointed to a need to study the relationship between program components and outcomes. Studying students' service-learning experiences can thus shed light on the ways in which particular educational environments and the individual components of those environments may facilitate integrative learning. The purpose of this study was to explore how students integrate learning from one particular experience, participating in a service-learning-based alternative break (AB), with other postsecondary and postgraduate experiences and to identify the conditions within $A B s$ that may facilitate integrative learning.

\section{Theoretical framework}

This study drew primarily from Barber's (2012) theory of integrative learning. According to Barber (2012),

Integration of learning is the demonstrated ability to connect, apply, and/or synthesize information coherently from disparate contexts and perspectives, and make use of these new insights in multiple contexts. This includes the ability to connect the domain of ideas and philosophies to everyday experiences, from one field of study or discipline to another, from the past to the present, between campus and community life, from one part to the whole, from the abstract to the concrete, among multiple identity roles-and vice versa. (p. 593) 
Barber's (2012) theory focuses on the process of integration rather than on the content of the learning itself. Barber (2012) gave examples of the types of learning students were integrating, including ideas about Plato and experiences playing Sudoku or building a homecoming float.

In a study of almost 200 undergraduate students, Barber (2012) identified three types of integration-connection, application, and synthesis-that demonstrated increasing cognitive complexity. Barber (2012) defined connection as "find[ing] a common thread between concepts or experiences that remain distinct; identifying similar elements, foundation, or characteristics" (p. 601) and noted that connections can be temporary, in the moment, and coincidental or can span longer periods of time (e.g., connecting high school and college experiences). Despite the range of ways in which students can connect ideas and experiences, "the defining characteristics of the Connection category of integration of learning is the establishment of a link that associates two or more ideas" (p. 603).

Often building on connections, the next most complex form of integrative learning was application, or "an action on the student's part to make use of knowledge within a new context" (Barber, 2012, p. 600). Importantly, application can involve the application of ideas (e.g., applying a perspective on writing learned in a writing course to writing experiences outside of the classroom) or skills (e.g., applying skills gained in helping with construction projects around the house in high school to constructing a homecoming float). Regardless of what is being applied and in which contexts, Barber (2012) explained that the "two main characteristics of the Application category of integration [are] the mobility of knowledge across contexts and the active role of the student in this mobility" (p. 605).

Finally, Barber (2012) identified the most complex form of integration as synthesis, where "two or more ideas or skills are brought together to create a new whole; combining knowledge to enhance understanding and gain new insight" (p. 601). Barber (2012) noted that synthesis was often linked to connection in that a student makes a connection between two ideas or experiences, "compares and contrasts them, and then takes [his or her] thinking further in order to synthesize them" (p. 606). The key characteristic of synthesis is "the fusion of two or more ideas, perspectives, or items to form a new view ... In the act of synthesis, there is a creation of something greater than the sum of its parts" (p. 606).

Although Barber (2012) found that integrative learning was distinct from other learning processes, a number of related theoretical perspectives can provide insight into how and why students are (and are not) engaging in integration. Of particular relevance to both Barber's (2012) theory and the present study are the theories of transfer of learning (Perkins \& Salomon, 1988, 1992; Tuomi-Gröhn \& Engeström, 2003). Transfer-of-learning theories are based on the assumption that learning is a question of the ability to transfer knowledge 
from one setting to another (Perkins \& Salomon, 1992). Thorndike, one of the pioneers of research on transfer of learning, "concluded that transfer depended on 'identical elements' in two performances" (Perkins \& Salomon, 1992, p. 6), but later learning theorists, such as Judd, rejected Thorndike's idea of "identical elements" in favor of focusing on the transfer of general principles between contexts (Tuomi-Gröhn \& Engeström, 2003).

Bridging Thorndike and Judd's early work on transfer of learning, Perkins and Salomon (1992) argued there are two kinds of transfer-"low-road" or simple forms of transfer among similar contexts and "high-road" or more complex forms of transfer among more disparate contexts. Importantly, transfer, particularly high-road transfer, does not happen automatically (Perkins \& Salomon, 1988; Tuomi-Gröhn \& Engeström, 2003). Complex transfer often requires intentional "bridging" (Perkins \& Salomon, 1988, p. 28), wherein educators help students make analogies between and among different contexts or point out general abstract principles that one might extract from specific examples.

Barber (2012) noted that although transfer and integration of learning are related, "integration of learning is a more complex, integrative phenomenon than transfer" (p. 608). Yet, theories of transfer can illuminate some of the dynamics within the process of integrative learning and the challenges of integrating learning across different contexts. Barber (2012) noted that some simpler forms of connection mirrored Perkins and Salomon's (1992) concept of low-road transfer, although other forms of connection were more complex. Barber (2012) also noted that application was the most closely related form of integrative learning to transfer of learning and that synthesis often (although again, not always) involved high-road transfer between very different contexts.

\section{Contexts that facilitate integrative learning}

Although there is some literature pointing to different experiences that may facilitate integration, Barber (2012) argued that more research is needed on the specific contexts that facilitate integrative learning. As Barber (2012) and others (e.g., Wawrzynski \& Baldwin, 2014) have noted, integrative learning does not just happen in the classroom; integration requires the ability to make connections across multiple contexts and experiences, including those that happen outside of the formal curriculum. One cocurricular context that may be particularly well suited to integrative learning is participation in a service-learning based $A B$. $A B$ s are short-term, immersive service-learning experiences where small groups of students (usually 10-15) engage in service-learning during their academic breaks, often in a different city, state, or country than where they are attending college.

Although little, if any, research on $A B$ s has specifically focused on integrative learning, research has indicated that $A B s$ and other service-learning experiences 
have the potential to facilitate aspects of integrative learning. For example, Jones, Rowan-Kenyon, Ireland, Niehaus, and Skendall (2012) found that students participating in short-term immersion programs (including ABs) deepened their understanding of social issues by connecting these issues to community members' lived experiences. Students were "able to put a name and a face" on the social issues about which they were learning, to compare "their own lives with the lives of the people they met" (p. 209), and to apply this knowledge to classroom conversations about social issues when they returned to campus. Niehaus and Inkelas (2015) similarly found that after returning from an $A B$ experience, many students were able to connect their $A B$ to their career plans in a variety of ways. Although they did not explore how students integrated their ABs with later career experiences, they did demonstrate that students had an interest in connecting and applying what they learned during their $A B$ s to their careers. In studies of longer-term service-learning programs, Sessa, Natale, London, and Hopkins (2010) found that students enrolled in a service-learning course were more inclined to integrate "ideas from different sources and even different classes" (p. 14) than were peers in a non-service-learning course, and Hughes and colleagues (2012) documented how students integrated their service experience in high-poverty environments with classroom learning about inequality.

Although there is some evidence that students who participate in $A B s$ and other service-learning are integrating learning from these experiences, it is also clear it does not happen automatically or for all students. Einfield and Collins (2008) noted that only some students in the AmeriCorps program that they studied were able to integrate their service with a broader understanding of social justice. They also questioned the integrative potential of short-term experiences like ABs. Similarly, Jones et al. (2012) found that despite the connections students made during their immersion experiences, many found it challenging to integrate what they had learned with their lives back on campus. This finding raises the important question of what types of experiences are most conducive to integrative learning.

Previous research on $A B s$ and other service-learning programs can shed light on what components of an $A B$ might best facilitate integrative learning, including direct education, reflection, pretrip preparation, posttrip support, and opportunities to interact with people different from oneself. Direct education is the "learning" half of service-learning. Eyler and Giles (1999) found that relevant classroom education was a significant predictor of students' ability to apply what they were learning to real-life problems, and Hughes et al. (2012) identified the importance of learning about poverty to students' ability to integrate their classroom and service-based learning. Reflection, one of the most cited best practices in service-learning broadly, is what links this direct education with the service experience (Hughes et al., 2012). As with direct education, Eyler and Giles found a positive relationship between reflection and application. 
What happens before and after the $A B$ experience is also likely to be an important factor in integrative learning. As most $A B s$ are cocurricular, pretrip orientation sessions can provide some of the foundational education that students need to understand the issues they will encounter during their trip (Elble, 2009). Posttrip sessions that provide additional support for students may help them overcome some of the challenges they face returning to campus (e.g., Jones et al., 2012) and can provide them with opportunities to continue to be involved. Niehaus and Inkelas (2015) found that a comprehensive reorientation program was a significant predictor of how much students reported that their $A B$ experience influenced their career plans, and Niehaus (2017) found a positive relationship between reorientation experiences and self-reported changes in diversity orientation one year after students returned from an $A B$.

Finally, an important feature of $A B s$ is that they provide opportunities for students to interact with and learn from people different from themselves, including community members and other students (Jones et al., 2012; Niehaus, 2016). These types of informal interactions with diverse others challenge students' existing worldviews, a necessary condition for learning (Gurin, Dey, Hurtado, \& Gurin, 2002). As Jones and colleagues (2012) found, it was through developing relationships with community members and peers that students were able to connect their immersion experiences to broader social issues. Niehaus (2017) also found that the extent to which students reported learning from others was a significant predictor of self-reported changes in social justice orientation one year after the $A B$.

Despite the documented potential for $A B s$ to contribute to positive student outcomes, often studies of ABs (and other service-learning experiences) are done in isolation, disconnected from students' broader life experiences, thereby limiting researchers' ability to identify and explore how and why students are (or are not) integrating learning across contexts. As such, the purpose of this study was to explore how students integrated their learning and experiences before, during, and after an $A B$. In particular, we sought to answer the following research questions:

(1) To what extent and in what ways do students who participated in ABs engage in integrative learning related to their $A B$ ?

(2) What experiences within ABs facilitate integrative learning?

(3) What barriers to integrative learning do students experience related to their ABs?

\section{Methods}

Data for this study came from the National Survey of Alternative Breaks (NSAB), a longitudinal, mixed-methods study of students who participated in 
ABs during the spring of 2011. Data for the NSAB were collected in three phases: a survey of students immediately after they returned from their ABs (Phase 1), a follow-up survey of those same students one year after their ABs (Phase 2), and in-depth interviews of students who had completed both surveys 1.5 to 2.5 years after their $A B$ (Phase 3 ). Although this study primarily drew from the qualitative Phase 3 data, we also used the survey data to inform the questions asked of each participant and to provide background information about students and their $A B$ experiences.

\section{Sampling and data collection}

During Phase 1, we drew a random, stratified sample of institutions with $A B$ programs based on institutions' basic Carnegie classification and size to ensure a broad range of institutions in the sample. Large, public institutions were intentionally oversampled to ensure an adequate sample size. Within each institution, all students who participated in ABs during the spring of 2011 were invited to participate in the survey; more than 2,000 students completed the survey (a response rate of approximately $35 \%$ ). One year later, all students who completed the first survey and provided a valid e-mail address were invited to complete a follow-up survey; 558 students completed the survey (a response rate of approximately $30 \%$ ).

Based on preliminary findings from the quantitative phases, we developed a follow-up interview protocol to explore students' experiences before, during, and after their $2011 \mathrm{AB}$. This phase of the NSAB employed an instrumental, collective case-study design (Merriam, 2001; Stake, 1995, 2006), wherein each student participant was considered a bounded case. This design allowed us to explore the complexities of each individual student's experiences and to compare across cases (Stake, 2006).

All students who indicated a willingness to participate in an interview on the second survey were invited to participate in the qualitative phase of the project. Interviews were conducted via phone or Skype and took place 1.5 to 2.5 years after students' $A B$. During the interviews, students were asked to expand on many of their survey responses (e.g., if students indicated that their $A B$ had influenced their plans to volunteer, they were asked to explain how so) and to discuss how the experiences they had before, during, or after their $A B$ (which were also reported on the surveys) were or were not related to each other. Because students' interview questions were based on their survey responses, each interview protocol was unique; however, they all followed the same basic template (see the Appendix for a sample interview protocol).

A total of 38 students participated in the interviews and had usable interview transcripts (due to technical difficulties, a few students' interviews were not recorded and transcribed so were not included in the analysis). Participants in the 
qualitative phase of the NSAB represented 26 different institutions across the United States and participated in 36 ABs. At the time of their 2011 AB, 7 participants were first-year students, 9 were sophomores, 5 were juniors, 12 were seniors, 1 was working on a second bachelor's degree, and 2 were graduate students (2 did not provide this information). Twenty-eight participants identified as women and 10 identified as men; 33 identified as White, 1 identified as African American, 1 identified as African American and Hispanic, 2 identified as Asian/Pacific Islander, and 1 identified as Asian/Pacific Islander and Hispanic.

\section{Data analysis}

In analyzing our data, we sought first to understand each individual as a case and drew from participants' interviews and background survey data. As case study methodology generally provides little guidance for how researchers should analyze data, we turned to narrative inquiry (Connelly \& Clandinin, 1990; Polkinghorne, 1995) to inform our analysis. Narrative inquiry was particularly relevant to our study because it allowed us to examine how students experienced their lives before, during, and after their $A B$.

In the within-case analysis, we employed "narrative analysis" (Polkinghorne, 1995, p. 12) to move from individual data elements (from interviews and surveys) to a narrative account of each student's experiences. This process was largely guided by chronology, centered on the student's 2011 AB. At least two researchers worked together to examine each student's data and develop one narrative at a time (Stake, 2006). At least one other researcher then reviewed each narrative for clarity, accuracy, and completeness.

Next, we turned to cross-case analysis (Stake, 2006) where we employed "analysis of narratives," moving "from stories to common elements" (Polkinghorne, 1995, p. 12). We first identified key plot elements within each story (motivation, previous experiences, pretrip preparation, key trip experiences, new perspectives, posttrip intentions, and posttrip actions) and then sought to identify chains of plot elements that were indicative of narrative arcs within each student's experiences. Two separate research team members coded each story for individual plot elements and chains of plot elements to ensure trustworthiness.

At this point, we found that the themes we were identifying closely mirrored Barber's (2012) theory of integrative learning, so we returned to the narratives for additional coding. In the first round of coding, we used a deductive approach to code students' integrative learning experiences (based on Barber's definitions of connection, application, and synthesis); at the same time, we used an open coding approach to code relevant experiences before, during, and after the $A B$ that were related to integrative learning. During this phase, we also developed a broad code for barriers to integration to identify anything that students discussed that prevented them from integrating learning across contexts. 
To identify the frequency and ways in which students integrated learning related to their $A B s$, we counted the number of times we had coded each type of integrative learning and engaged in open coding within each category to identify themes in how students were connecting, applying, and synthesizing. We then looked to our coding of students' pre- and post-AB experiences (e.g., other service experiences, coursework, jobs or internships, etc.) to identify the most common experiences that students were integrating with their ABs. Next, we explored how often and in what ways students referred to various aspects of their $A B$ experience (e.g., reflection, interactions with community members, etc.) in discussing integrative learning to identify common facilitators of integration. Finally, we engaged in open coding within our broad category of barriers to integration to identify themes in what may have prevented students from integrating learning.

\section{Findings}

We found that although not everything in students' stories related to integrative learning, applying this lens helped us describe some of the most salient features of students' experiences before, during, and after an $A B$; in fact, we identified at least some form of integration in all 38 participants' stories. We also found wide variation in students' abilities to integrate learning from their $A B s$ with other aspects of their lives.

\section{Connection}

Connection was the most frequent type of integrative learning evidenced in our data-all 38 participants had examples of connection, for a total of 348 different instances of connection. Students were most often connecting their $A B s$ to other service experiences before (27 participants) or after (30 participants) their ABs, coursework before (12 participants) or after (16 participants) their $A B s$, previous cross-cultural experiences (12 participants), or subsequent job or internship experiences (26 participants). Coding within the category of connection showed that participants were making a number of different types of connections, ranging in complexity. Students remarked on basic linkages between or among experiences; compared and contrasted experiences, people, places, and perspectives; related their experiences to their own lives and/or communities; and connected ideas and experiences.

\section{Basic linkages and motivation}

At the most basic level, we saw students drawing connections between different experiences_-often different service experiences, but also connecting 
their $A B$ and coursework, majors, or career plans. Hank, for example, remarked that "doing construction [on the $A B$ trip] reminds me of why I'm getting my undergraduate degree," and Jackie noted that the focus of her AB on wellness connected nicely to her major in athletic training. On a somewhat more involved level, a number of participants noted that different experiences were connected through their overall motivation to engage in service or pursue a particular career path. Nicole connected her AB and other service experiences to her graduate degree in social work, which she was pursuing at the time of the interview. She explained that her service experiences "continually reaffirm[ed] that I'm in the right profession." Other students looked backward in time and noted their previous experiences were really their motivation for signing up for the $A B$ initially. Molly noted that her previous service experiences were an important factor in the types of ABs in which she was most interested because she was not "afraid to go on a mission trip because I had already done two."

\section{Comparing and contrasting}

Going beyond noting simple links between experiences, the most common form of connection was evidenced by students comparing and contrasting different experiences, locations, people, and perspectives. Students made these types of connections across experiences before, during, and after their ABs. Many students compared multiple ABs. Nicole discussed some of the similarities and differences between her ABs in Ecuador and West Virginia. She described both areas as "experiencing poverty," but in Ecuador, she said, the poverty situation was "more extreme." There were issues in Ecuador with getting clean water, which Nicole thought were also likely occurring in West Virginia.

Other students drew comparisons between their ABs and other service activities or travel. Sarah compared her experience traveling to Guatemala to her previous experience traveling to Europe with her parents and noted that

traveling to Europe with my family that can support me is so much different than what I did in traveling on my alternative spring break ... [and] the culture of where I was in Europe and stuff, it's so different from where I was in Guatemala.

Maggie contrasted her $A B$ experience to her experience volunteering at a local childcare facility after she returned to campus. In particular, she compared the two different schools where she volunteered during each experience. She noted the schools were "polar opposites" and that it was "really interesting to see how different it is from just being in the schools for one day [during the $A B]$, then to go home and be working at the nicest school in [my home state]." 


\section{Linking experience to self}

An increasingly complex form of connecting in students' stories was between ABs and participants' own lives-either connections to their personal experiences or back to their own home or school communities. Helen connected what she learned about access to education on her AB to her own educational experiences and remarked, "I always thought education was very important. I guess after the trip, I realized how hard it is for a lot of people to follow the same path of education that I've been on my whole life." Mary similarly noted how her AB experience led her to reflect on her identity as a White person. She explained, "I definitely feel like I have a lot more privilege than other races ... my life has been pretty easy compared to a lot of people."

Participants were also able to connect their $A B s$ to their hometowns or campus communities. Mary Kate, who remarked that before her $A B$, she had never really thought much about rural poverty, explained that after she returned home she began to notice the rural poverty in her own community. She described,

when I drive up to my cottage, we pass through a number of rural areas, where before I might have just considered them a little junky ... but I never really thought about why it might be like that or the fact that it's not just junky or rundown, it's that people there are very poor and there's a reason for that.

Alexandra reflected on the similarities she saw between community violence issues on her $A B$ and what she observed of those same issues near her campus. She described that both communities were "fairly poor. They really struggle with a lot of community violence ... it was really interesting to discuss that, what they were doing to kind of stop community violence, compared to what we were doing."

\section{Linking ideas and experiences}

The final and most complex type of connection that participants described was in the links that they made between ideas and experience. Sean described connecting his knowledge of HIV with his $A B$ experience working in a shelter for HIV-positive individuals; he described that the conversations he had with people at the shelter "put a human face" on the issue for him. Steven connected his real-world experience in Nicaragua to his previous sustainability coursework. He explained,

it was a really rough day in Nicaragua when the village runs out of water for several hours and that experience kind of goes to how great sustainability impacts everything ... I've read about it in books but to be like, sorry we can't mix cement, you can't go to the bathroom or flush the toilet, there's no water, that brings it to a whole new level. 
Other students made this type of connection between their AB experience and things they learned or experienced afterward. Rebecca took a course on "U.S. Society in Critical Perspective" after her AB. She described,

From my trip, I have been exposed to the fact that ... there's not one answer, there's not one solution, and that class kind of opened my eyes to the fact that housing isn't the only problem where there's not just one solution.

\section{Application}

Instances of application (98 total) were less frequent than instances of connection, although we did find evidence of application in 31 participants' experiences. Students occasionally discussed application from previous experiences to the $A B$, but they more frequently discussed applying something learned in the $A B$ to subsequent experiences. The most frequently cited posttrip experiences relating to application were post-AB service and jobs or internships (17 participants each). Coding within the category of application identified two different types of application: application of skills and of ideas. Although there were some similarities in the ways that students were engaging in connection and application, the key feature that distinguished application from connection was that application required participants' intentional engagement in some behavior or action.

\section{Application of skills}

Some participants discussed how they were able to apply particular skills they had learned in previous experiences (often service-related) to their ABs. Michelle had frequently volunteered at an animal shelter near home during high school and developed a number of animal-care skills that she was able to apply to her $A B$ at an animal shelter in New Orleans, LA. She explained, "When it came time to bathe the dogs and groom them, we had to trim their nails and stuff and I had done that all before." Similarly, other participants discussed applying what they learned in $A B$ to other experiences. After participating in multiple ABs, Gabby started to intern for the office on her campus that organized service trips. In that role, she was asked to organize the reflection/education portion of the projects. It was a role that she felt prepared for because "all my knowledge of dialogue facilitation was pretty much borne out of my time with $A B$. So I think I came to that with almost like being super intentional about everything that I was doing." Faith also described learning how to facilitate small-group activities and reflections during her $A B$, which she was able to apply to facilitating lessons when she spent the summer volunteering at a school in Kenya.

Many students also discussed taking the skills they developed during their $A B s$ into their future careers. Nicole described the relationship-building skills she developed in her $A B$ and how important they were to her role as a social worker. 
Creating "two-directional" relationships took time and energy, and as a social worker, Nicole would remind herself of this when she was "feeling tired" getting through an awkward conversation. Debbie also referenced the importance of empathy, a skill she developed in her $A B$ and later applied in her nursing career.

\section{Application of ideas}

Participants returned from their ABs with a variety of new ideas and perspectives, which they applied to the way they approached subsequent experiences in service, their careers, and everyday life. At times, these examples of application were similar to the connection examples related to motivation or connecting ideas and experience, but in the connection category, the examples tended to be more basic linkages between two experiences, while in the application category, students were explicitly using ideas from one context to influence their behaviors in another.

Participants often discussed how they were able to take ideas from their ABs and apply them to other service experiences. Tiffany came to realize the importance of volunteering during her $A B$, which she later applied to a volunteer position at the local hospital. She described,

every Monday at 5:30 a.m., I go and volunteer at the emergency room. And most Mondays, it's really not that pleasant to get up that early and go and deal with sick people for hours on end, but there's that sense of well, if you can do this for a week [on an AB], you can do this for 3 hours. But it's just the idea that we all have to pitch in. We all have to help each other out; if not me, then who?

Others related the ways the ideas they took from their $A B$ influenced how they approached their careers. Stacy described how her AB experiences helped her recognize hunger issues in her job as a public health nurse after graduating. She noted that the experience helped her "think more holistically about my patients and the poverty and hunger issues they may be facing." She explained,

I get assigned a client I get the referral for because they need medicine. But when you get there, [they can't] take their medicine if they have no food. So I do always think about that, and check their refrigerator, and talk to them about that, and provide them with resources ... [and] it probably is because of-partly because of that trip that I think about those things.

Participants also applied the ideas they developed during their $A B$ s to smaller everyday behaviors. Clarissa described trying to recycle more after her $A B$, and Hannah noted she tries to treat people experiencing homelessness differently as a result of her AB. She explained that now, when she sees a homeless person on the streets, 
I'm always, you know, gonna look them in the eye and say hello to them, ask them how their day was, because if that was me, that's how I would wanna be treated. And the people who I've worked with in all of these different cities [through $A B s$ ], I've realized that they're my friends, people who I care about, so if I saw them on the streets, I would do that.

\section{Synthesis}

Synthesis was the least common form of integration exhibited by participants with 22 total examples, but still more than half of the students in this study (20 students) demonstrated at least some synthesis of learning related to their $A B$. Students combined learning from their $A B$ most frequently with previous service experiences (4 participants), previous cross-cultural experiences (3 participants), or subsequent job or internship experiences (2 participants), but they also combined it with what they learned from the media and their own family experiences. Some participants even synthesized different experiences within the same $A B$ to create new ideas and understandings. Gabby related how she was able to connect what she was seeing about disaster relief in New Orleans with the personal experiences that a student she was tutoring during the $A B$ shared with her. This led to a new understanding about the complex relationship between social class and disaster relief and how these experiences would influence this child's future. She learned how he

had faced a great deal of trauma in his own life and that at age three a lot had happened to him ... and then I started making connections between sort of his living situation and how a disaster can lead up to those things. So his family is completely without resources and I knew how the disaster and how class played into that and to his current social situation and then how that would play out for the rest of his life.

As Barber (2012) described in his findings, Gabby's experience of integrative learning started with connecting two ideas or experiences (what she was learning about disaster relief and what she was learning from the child she was tutoring) but then extended to a completely new understanding of social class.

Damien similarly was able to connect what he had read in the news about disasters affecting "predominantly White areas such as the Missouri tornado" with what he saw in a predominantly Black community in New Orleans. This connection led to a new understanding of race and racism in the United States. He observed that in Missouri, "they instantly got aid," and in New Orleans, "when they got hit with Hurricane Katrina, barely any help was sent there." For Damien, being able to see and experience firsthand what happened and "the lack of aid that was sent down" showed him flaws in society. Damien explained,

Just because we have a Black president doesn't mean we're in postracist society. Racial discrimination is still out there, but ... it's no longer as overt as it 
once was; it's hidden and it manifests itself in different ways such as lack of aid sent down to places where there's a high minority rate.

Damien's learning went beyond just what he was seeing in connecting disaster relief efforts in Missouri and New Orleans to a new, broader understanding of structural racism.

\section{Facilitators of integration}

In exploring the factors within $A B s$ that were most frequently linked to students' experiences integrating learning across all three categories (connection, application, and synthesis), we found that surprisingly, there were a number of within- $A B$ experiences that were not frequently linked to integrative learning in our data, despite evidence in the literature that they may be. Reflection, for example, was only linked to connection for 6 participants, application for 3, and synthesis for 2. Pretrip orientation or preparation was only linked to connection for 5 participants, and posttrip reorientation experiences were only linked to connection for 1 participant; no participants cited either as being linked to application or synthesis. We also rarely found evidence that educators were helping students integrate learning. However, we did find a consistent theme that the most important part of the $A B$ experience for students' integrative learning was participants' experiences interacting with other people. Interactions with community members were linked to connection for 24 participants and to synthesis for 9 participants; interactions with other students were linked to connection for 14 participants and to application for 7 participants.

\section{Community interactions}

Interactions with community members often provided the basis for students to compare and contrast experiences, link experiences to self, and link and apply ideas and experience. Through interactions with community members, Steven was able to notice similarities between the food and religion in Guatemala and Nicaragua (the sites of his two ABs) and also to compare community members' experiences in each country's civil war. He explained,

The conversations we had with-in Guatemala for the first week with kind of the village elders, the people who had lived through the civil war and in $\mathrm{Ni}$ caragua [were] kind of the same. A different civil war, but the two guys I was the closest with [in each country] were actually like special unit commando fighters in the civil war.

Debbie similarly noted that her interactions with community members allowed her to learn about how people in different cultures were different from her. She described,

You learn a lot about just the way things are ... The dress was different. The color of the people was different ... But the attitudes were a lot different. The 
things they valued were a lot different. So those are aspects of the culture I saw a difference in.

Many of the connections that students made between ideas and their $A B$ experiences were also facilitated by their interactions with community members. As previously described, Sean was able to connect his knowledge of HIV with his $A B$ experience, and he described that his interactions with community members "kinda put a human face" on the broader issue of HIV. Similarly, some students were able to take ideas that they had learned from interacting with others and apply them after their $A B$ ended. Eileen discussed how prior to her $A B$, she had little appreciation for organized religion, but during her $A B$, she saw "the role that religion played in Habitat and the other participants' lives and the family as well that we were building the house for." As a result of coming to understand the role that religion played in the lives of community members, other students, and Habitat staff, Eileen began to act more respectfully of others' religious beliefs after her AB.

Some students went beyond connection and application in their experiences with community members and were able to synthesize new perspectives based on those interactions. As previously described, Gabby's experience tutoring a child in New Orleans combined with her growing knowledge about disaster relief from other experiences during her $A B$ allowed her to come to a new understanding about the complexities of the relationship between social class and disaster relief. Clarissa also discussed how her encounters with different community members helped her develop a more complex understanding of homelessness. Comparing and contrasting different community members' experiences "completely ... changed my outlook on [people experiencing homelessness] ... they're just really amazing people. You just have to talk to them and get their story."

\section{Student interactions}

Like their interactions with community members, participants' interactions with other students participating in the same $A B$ program often provided opportunities to compare and contrast different perspectives and ideas. Daniel described how the unique and sometimes strong personalities present among his $A B$ team were valuable to his learning. Although Daniel was engaging in the same service activities each day as other team members, his team members interpreted and derived different meanings from them. He explained that "seeing everyone else's perspectives who had gone through teaching classes and who just had different ideas and different styles for what they think good teachers should look like and what they should do and stuff was just kinda neat." James was also able to contrast his own extensive experiences with camping to those of his peers, noting that being on the trip with other students

who had never been camping before or had never been hiking before ... really showed me a different perspective ... realizing that people in the majority 
of our societies just don't realize what's out there until they go outside their comfort zone and try something new.

Participants were also able to develop skills through working with other students and then apply those skills in other contexts. Gaile described how she developed communication skills during her first $A B$ through regular discussions with her peers. She explained,

[W] could see how the other crew members were feeling about the day and stuff. I mean at work if you don't communicate with your coworkers all the sudden the job's not going to get done; it's not going to get done as easily as it could be done. I definitely think $[A B]$ taught me how all kinds of groups work and how people need to communicate in a group in order for ... everybody to be happy.

Gaile was able to apply this lesson to her life in college when she served as a trip leader for two additional $A B$ trips. Other students reflected on the importance of the relationship-building skills that they had developed through their interactions with other students and how they were able to apply those skills in their future lives and careers. As described, Nicole learned how to build "twodirectional" relationships based on openness and trust through building those types of relationships with other students during her $A B$, and this skill was vital to her later career as a social worker.

\section{Barriers to integration}

Although we found a great deal of evidence that integrative learning was happening before, during, and after participants' ABs, we also identified 32 examples from 22 participants of times when students encountered specific barriers to connecting, applying, or synthesizing. A few examples related to weaknesses in the $A B$ program itself-lack of direct education or reflection, ineffective pretrip preparation, or problematic service placements. More frequently, students cited lack of opportunity to build on their experiences (either lack of service opportunities or related job/career opportunities) or lack of time to continue to engage in service. Ali, for example, wanted to volunteer with a national service program, but she felt "there isn't really a long-term program like that that I could do for what I've trained in, and that was health care-related." Nicole described how, despite her interest in participating in a year of a service program after her $A B$, "life kind of got in the way." Hank similarly noted that despite his desire to stay involved with Habitat after his $A B$, he felt "like I'm stretched out every other way that there's not much time for that."

The most frequently discussed barrier to integration, however, was that students saw what was happening on their $A B$ as so different from their other experiences that they were unable to connect the two (and as a result, they were similarly unable to engage in other forms of integration). Mustafa noted that 
despite his overall interest in service and the fact that he volunteered with Habitat after his $A B$, he did not really connect his $A B$ to these other experiences. He explained,

$[A B]$ just seemed very separate from [other experiences with Habitat] because it was a one-time thing whereas the other commitments that I had in community services were recurring so it felt a little bit different ... and I guess part of it is that we weren't in [my college town], we weren't at school so it was just very-it was a very removed experience from [college].

Sara similarly saw the issues she encountered on her AB in Guatemala as being fundamentally different than anything that happened in the United States. As she described, she did not really see any connection between what she learned in Guatemala and issues of hunger in her own community. She explained, "I don't really relate it to back here ... it made me realize that more in third-world countries, the area that we were in [in] Guatemala, that made it more clear for me, but here, it's like-it's really different." For Sara, issues of poverty and hunger remained problems elsewhere.

\section{Discussion and implications}

Although learning theorists have been discussing issues related to the transfer or integration of learning for more than a century (Perkins \& Salomon, 1992), the demands of the 21 st-century world require students to develop the ability to connect, apply, and synthesize-to integrate learning across multiple contexts. Despite evidence that students are engaging in integration in and out of the classroom, often educators are falling short in supporting students in this process (Barber, 2012). From exploring integrative learning in one particular context, $A B$ programs, the findings from this study can inform our understanding of how students are engaging in integration and improve our understanding of how educators can best support integration in higher education. In this section, we will discuss how our findings connect to the previous literature and help us come to a deeper understanding of the process of integrative learning. We will then discuss the conditions that facilitate and inhibit students' ability to integrate learning and the role that educators can play in promoting this important 21st-century skill. Finally, we discuss the limitations of this study and directions for future research.

\section{Understanding integrative learning}

Consistent with Barber's (2012) work on integrative learning, we found that the vast majority of students in our study were engaging in some form of integration. We also found support for Barber's (2012) three types of 
integration-connection, application and synthesis-and described how students engage in each of these three types of integration related to ABs. The specific examples of how students are connecting, applying, and synthesizing learning among multiple curricular and cocurricular experiences, including but not limited to their $A B$ experiences, helps us understand more about what integrative learning looks like in practice.

Despite concerns about the potential of such short-term programs to facilitate integration (e.g., Einfeld \& Collins, 2008), we did find that students were engaged in connection, application, and synthesis related to their ABs. One particularly important form of connection was the links that many students were able to make between their $A B s$ and their own communities; $A B s$ are often not isolated experiences for students, but rather experiences that contribute to students' continued commitment to service. Many students were also able to take the skills and perspectives they learned in their ABs into their future careers, making them more thoughtful, caring, and effective professionals and extending the impact of the $A B$ experience well beyond the students and communities directly involved. The ways in which students integrated their $A B s$ with subsequent service, internship, and job experiences, even after graduation, are particularly noteworthy, as Barber's (2012) study only examined students' experiences of integrative learning during the first two years of college. Integrative learning is a lifelong process, and future research should focus on the ways in which students integrate learning from various experiences over time.

Our findings also point to the potential for curricular and cocurricular experiences to be mutually reinforcing. Barber (2012) argued that learning can happen both in and out of the classroom, and our findings provide examples of how students are integrating that in-classroom and out-of-classroom learning. As described, Steven was able to see the idea of water shortages, about which he had learned in his courses, play out in real life in Nicaragua. This experience enhanced his learning about sustainability. Rebecca similarly was able to connect her $A B$ experience to her later coursework, helping her think more complexly about social issues in both contexts. Wawrzynski and Baldwin (2014) argued that "too often key elements of the college experience are disconnected and not mutually reinforcing" (p. 51). Although there remains room for improvement in this area, our findings optimistically point to the potential to create more connected learning experiences in college.

\section{Facilitators of and barriers to integration}

Similar to Barber's (2012) participants, we found that students were generally engaging in integration on their own, without intentional, explicit support for integrative learning from educators. However, we did find environmental conditions that support integration, many of which are under the control of educators 
planning experiences like ABs. Importantly, unlike Barber (2012), who focused on programs and institutions "that are intentionally designed to promote integration of learning" (p. 589), we were able to identify conditions that promote integrative learning without that intentional focus.

We found that students engaged in more integrative learning when they were given the chance to learn from others. This was clearly conveyed in the findings where students often were able to compare and contrast their experiences to what they learned from diverse community members and peers, apply their learning in different contexts, and synthesize new ideas based on these interactions. As Jones et al. (2012) found in their study of short-term immersion programs, students often benefit most from immersion experiences when they are able to connect real people to the broader social issues being addressed in their $A B$. Much of the non-service-learning literature on diversity interactions focuses on interactions with diverse peers (e.g., Gurin et al., 2002), but our findings also point to the importance of engaging students with diverse community members to promote integrative learning. This can be done through intentionally designed service-learning programs, but educators working in other areas can also think of creative ways to engage students with the local community.

In discussing some of the reasons why students might not engage in integration, Barber (2014) explained, "Three of the key issues facing students in regard to learning are (a) compartmentalization, (b) the ever-increasing collection of digital tools available, and (c) a lack of opportunities for reflection" (p. 12). Our findings lend particular support to Barber's (2014) first and third points. We found that often students were unable to integrate learning across very different contexts because they were unable to see the similarities between or among those contexts. This finding also echoes Perkins and Salomon's (1988) assertion that high-road transfer, or transfer across divergent contexts, requires intentional bridging. We also found that few students reported integrative learning experiences related to structured reflection opportunities during their $A B s$, despite the fact that reflection is one of the key best practices in service-learning programs (e.g., Eyler \& Giles, 1999).

In addition to supporting Barber's (2012) points on the challenges of integration, we also identified the fact that often students have difficulty finding ways to continue to build on their $A B$ experiences, either through perceived lack of time or opportunity. This finding echoes Jones and colleagues' (2012) findings on the challenges that students faced in acting on what they had learned during their immersion experiences, often due to life constraints and pressures from family and friends. Our findings build on this previous work, however, by identifying it as a particular challenge for integrative learning that may extend beyond $\mathrm{ABs}$ and other immersion experiences. 


\section{Role of educators in integrative learning}

Although we did find that all our participants engaged in at least some form of integration related to their $\mathrm{ABs}$ and that there were environmental conditions that supported integration, we also noted some limitations to this integrative learning. We found that students tended to integrate learning from experiences where they were able to see clear similarities-for example, multiple ABs, other service experiences, or related courses. This finding mirrors Perkins and Salomon's (1992) idea of low-road transfer, which occurs between and among similar contexts. We also found that students engaged more frequently in what Barber (2012) identified as less complex forms of integration, connection and application, and less frequently in the more complex form of synthesis. There may be a number of reasons why we did not find more examples of high-road transfer or more complex forms of integration, but one possibility is that similar to Barber's (2012) findings, we found relatively few instances in students' stories of educators who had specifically facilitated students' abilities to integrate learning. More complex forms of transfer or integration require intentionality on the part of educators who can help students bridge different contexts and ideas (Perkins \& Salomon, 1988).

So how can educators more intentionally help students connect, apply, and synthesize learning across more disparate contexts? And how can educators push students to more cognitively complex forms of integration, even within similar contexts? Our findings help answer these questions in three ways.

First, our findings of how students are already engaging in integration can help educators identify the potential for integrative learning in different learning environments. A great deal of previous research has identified the importance of providing opportunities for students to engage with people different from themselves (e.g., Gurin et al., 2002), and our findings point to the additional importance of these diversity interactions in facilitating integrative learning. Educators working with $A B s$, service-learning, and many other types of curricular and cocurricular programs can promote integration by promoting interactions with diverse students and local community members.

Second, educators should be intentional about integrative learning before, during, and after an experience; this can help improve the integrative potential of program components such as reflection and direct education that should be facilitating integration but are often falling short. Educators can ask students to reflect on their previous experiences and how they relate to a current educational experience. Educators can also help students connect what they are learning to other contexts-for example, by asking them about courses they are taking or related examples they may be hearing about in local, national, and international news. Barber (2012) found that asking students about the connections between experiences during an interview was often enough to promote 
integrative learning in that moment; educators can similarly promote integration by simply asking students to do so.

Third, our findings point to key barriers to integration that educators can work to help students overcome. Educators can anticipate the challenges that students may face in connecting their experiences across very different contexts and can intentionally help them compare and contrast those experiences to promote integration. Educators can also help students anticipate time challenges and think of creative ways to overcome them, and they can intentionally provide opportunities for students to continue to build on their learning and experiences. Future research should explore the effectiveness of these ideas, along with other intentional interventions to promote integrative learning.

\section{Limitations and directions for future research}

As with any study, there are limitations to this study that point to the need for continued research on this topic. First, neither the quantitative nor qualitative phases of the NSAB were specifically designed to assess integration. Rather, integrative learning emerged as a particularly fitting framework during the qualitative data analysis. Future research should focus specifically on applying integrative learning to particular educational experiences. Second, although the data collection for the NSAB was longitudinal, the primary data for this study came from retrospective interviews conducted at least 1.5 years after students' $A B s$. This allowed us to explore how students were integrating multiple experiences before, during, and after their $A B s$, but we still relied on students' sometimes limited ability to recall details of their experiences and learning. We were able to use survey data during the interviews to jog students' memories about the details of their $A B s$, but multiple interviews over time would allow for perhaps a more accurate representation of how students integrated learning over time. At the same time, only having 1.5 to 2.5 years between the $A B$ and the interview also meant we may not have fully captured the ways in which students integrated learning from their ABs with experiences that happened much later in their lives. Although our study goes further than Barber's (2012) focus on just the first 2 years of college, there is still a need for more long-term research exploring how students integrate learning before, during, and well after college. Finally, although we were able to identify the experiences that students had before, during, and after their ABs that were related to their reports of integrative learning, we were not able to explain why some students more readily integrate learning than others. Further research should look at the interaction of personal and environmental factors in predicting integrative learning. 
Funding - This study was made possible by the NASPA Foundation, the ACPA Foundation, the National Association of Campus Activities, the University of Maryland College of Education, and the University of Maryland College Student Personnel Program McEwen Research Fund.

\section{References}

Barber, J. P. (2012). Integration of learning: A grounded theory analysis of college students' learning. American Educational Research Journal, 49, 590-617. doi:10.3102/0002831212437854

Barber, J. P. (2014). Integration of learning model: How college students integrate learning. New Directions for Higher Education, 2014(165), 7-17. doi:10.1002/he.20079

Connelly, F. M., \& Clandinin, D. J. (1990). Stories of experience and narrative inquiry. Educational Researcher, 19(5), 2-14. doi:10.3102/0013189X019005002

Einfeld, A., \& Collins, D. (2008). The relationship between service-learning, social justice, multicultural competence, and civic engagement. Journal of College Student Development, 49, 95-109. doi:10.1353/csd.2008.0017

Elble, A. E. (2009). The effect of a public health service-learning/study abroad program in Swaziland on the cultural awareness of university undergraduate students (Unpublished master's thesis). Purdue University, West Lafayette, IN.

Eyler, J., \& Giles, D. E. (1999). Where's the learning in service-learning? San Francisco, CA: Jossey- Bass.

Gurin, P., Dey, E. L., Hurtado, S., \& Gurin, G. (2002). Diversity and higher education: Theory and impact on educational outcomes. Harvard Educational Review, 72, 330-367. doi:10.17763/haer.72.3.01151786u134n051

Hovland, K., Anderson, C., \& Ferren, A. (2015). Interrogating integrative learning. Peer Review, 16/17(4/1). Retrieved from https://www.aacu.org/peerreview/2014-2015/ fall-winter/ferren

Hughes, C., Steinhorn, R., Davis, B., Beckrest, S., Boyd, E., \& Cashen, K. (2012). University based service-learning: Relating mentoring experiences to issues of poverty. Journal of College Student Development, 53, 767-782. doi:10.1353/csd.2012.0076

Jones, S. R., Rowan-Kenyon, H. T., Ireland, S. M.-Y., Niehaus, E., \& Skendall, K. C. (2012). The meaning students make as participants in short-term immersion programs. Journal of College Student Development, 53, 201-220. doi:10.1353/csd.2012.0026

Mansilla, V. B. (2008). Integrative learning: Setting the stage for a pedagogy of the contemporary. Peer Review, 10(4), 31. Retrieved from http://www.aacu.org/sites/default/ files/files/peerreview/PRFall08.pdf

Merriam, S. B. (2001). Qualitative research and case study applications in education: Revised and expanded from case study research in education. San Francisco, CA: Jossey-Bass.

Nelson Laird, T. F., Seifert, T. A., Pascarella, E. T., Mayhew, M. T., \& Blaich, C. F. (2014). Deeply affecting first-year students' thinking: Deep approaches to learning and three dimensions of cognitive development. The Journal of Higher Education, 85, 402-432. doi:10.1080/00221546.2014.11777333 
Neumann, A. (2014). Staking a claim on learning: What we should know about learning in higher education and why. The Review of Higher Education, 37, 249-267. doi:10.1353/ rhe.2014.0003

Niehaus, E. (2016). Alternative breaks as a context for informal interactions with diversity. Journal of Student Affairs Research and Practice, 53, 160-174. doi:10.1080/1949 6591.2016.1118382

Niehaus, E. (2017). Building momentum in student engagement: Alternative breaks and students' social justice and diversity orientation. Journal of College Student Development, 58, 53-70. doi:10.1353/csd.2017.0003

Niehaus, E., \& Inkelas, K. K. (2015). Exploring the role of alternative break programs in students' career development. Journal of Student Affairs Research and Practice, 52, 134-148. doi:10.1080/19496591.2015.1020247

Perkins, D., \& Salomon, G. (1988). Teaching for transfer. Educational Leadership, 46, 22-32.

Perkins, D., \& Salomon, G. (1992). Transfer of learning. In International encyclopedia of education (2nd ed.). Oxford, England: Pergamon Press.

Polkinghorne, D. E. (1995). Narrative configuration in qualitative analysis. International Journal of Qualitative Studies in Education, 8, 5-23. doi:10.1080/0951839950080103

Sessa, V. I., Natale, D. K., London, M., \& Hopkins, C. A. (2010). How students learn in a service-learning course: A quasi-experimental field study of generative learning. Journal of Community Engagement, 1(2), 1-20. doi:10.1080/0951839950080103

Stake, R. E. (1995). The art of case study research. Thousand Oaks, CA: Sage.

Stake, R. E. (2006). Multiple case study analysis. New York, NY: Guilford.

Tuomi-Gröhn, T., \& Engeström, Y. (2003). Conceptualizing transfer: From standard notions to developmental perspectives. In T. Tuomi-Gröhn \& Y. Engeström (Eds.), Between school and work: New perspectives on transfer and boundary-crossing (pp. 1938). Amsterdam, The Netherlands: Pergamon.

Wang, J. S., Pascarella, E. T., Nelson Laird, T. F., \& Ribera, A. K. (2015). How clear and organized classroom instruction and deep approaches to learning affect growth in critical thinking and need for cognition. Studies in Higher Education, 40, 1786-1807. doi:10.1080/ 03075079.2014.914911

Wawrzynski, M., \& Baldwin, R. (2014). Promoting high-impact student learning: Connecting key components of the collegiate experience. New Directions for Higher Education, 2014 (165), 51-62. doi:10.1002/he.20083 


\section{Appendix}

\section{Sample interview protocol}

Why did you decide to participate in an alternative break (AB) trip in the spring of 2011 ?

Did you participate in any pretrip activities to help you prepare for your experience?

What still stands out for you about your AB trip?

Can you tell me a bit about what you did during your AB trip?

I noticed that your trip focused on affordable housing. Why did you choose to do a trip focusing on affordable housing? Had you been involved in any activities related to affordable housing prior to the trip? What did you think about affordable housing issues before the trip? Has that changed at all as a result of your trip? Do you think your $A B$ experience influenced the way you see affordable housing issues in your own communities, either where you are from or where you go to school? Have you been involved in any activities related to affordable housing since returning from your trip?

What do you think was the most important part of the $A B$ experience for you?

Thinking back, what do you think you learned from your $A B$ experience?

What role did community members play in your learning?

What role did other students on the trip play in your learning?

What role did host site staff play in your learning?

Were there other people you think were instrumental in what you learned or got out of the experience?

I noticed in the online survey that you had previously participated in another $A B$. What effect do you think that had on your 2011 AB experience?

In the online survey, you indicated that your $A B$ experience influenced your future career plans. Can you tell me more about that? Have you found it easy to follow through with that? Where do you stand on that now?

From the online survey, it seems that your $A B$ experience helped you learn more about people different from yourself. Can you tell me more about that?

In the online survey, you indicated that you felt really overwhelmed when you returned from your $A B$ trip. Can you tell me more about that?

In the online survey, you said that during the year after your $A B$ experience, you studied abroad. Where did you go? Do you think your $A B$ trip influenced your experience at all? How so? Were you able to make any connections between what you learned from your $A B$ experience and what you learned from this activity?

Those are all the questions I have for you. Is there anything else that you would like to add that would help me understand your $A B$ experience 